\title{
Impact of palmitic acid coating on the water uptake and loss of ammonium sulfate particles
}

\author{
R. M. Garland ${ }^{1}$, M. E. Wise ${ }^{1 *}$, M. R. Beaver ${ }^{1}$, H. L. DeWitt ${ }^{1}$, A. C. Aiken ${ }^{1}$, J. L. Jimenez ${ }^{1}$, and M. A. Tolbert ${ }^{1}$ \\ ${ }^{1}$ Department of Chemistry and Biochemistry and CIRES, University of Colorado, Boulder, Colorado, USA \\ *now at: Department of Geological Sciences and Department of Chemistry and Biochemistry, Arizona State University, \\ Tempe, Arizona, USA
}

Received: 7 February 2005 - Published in Atmos. Chem. Phys. Discuss.: 6 April 2005

Revised: 30 June 2005 - Accepted: 30 June 2005 - Published: 1 August 2005

\begin{abstract}
While water insoluble organics are prevalent in the atmosphere, it is not clear how the presence of such species alters the chemical and physical properties of atmospheric aerosols. Here we use a combination of FTIR spectroscopy, Transmission Electron Microscopy (TEM) and Aerosol Mass Spectrometry (AMS) to characterize ammonium sulfate particles coated with palmitic acid. Coated aerosols were generated by atomizing pure ammonium sulfate, mixing the particles with a heated flow of nitrogen with palmitic acid vapor, and then flowing the mixture through an in-line oven to create internally mixed particles. The mixing state of the particles was probed using the AMS data and images from the TEM. Both of these probes suggest that the particles were internally mixed. Water uptake by the mixed particles was then probed at $273 \mathrm{~K}$. It was found that for ammonium sulfate containing $\sim 20 \mathrm{wt} \%$ palmitic acid the deliquescence relative humidity (DRH) was the same as for pure ammonium sulfate $(80 \pm 3 \%$ $\mathrm{RH})$. For particles with $\sim 50 \mathrm{wt} \%$ palmitic acid however, the mixed particles began to take up water at relative humidities as low at $69 \%$ and continued to slowly take up water to $85 \% \mathrm{RH}$ without fully deliquescing. In addition to studies of water uptake, water loss was also investigated. Here coatings of up to $50 \mathrm{wt} \%$ had no impact on the efflorescence relative humidity. These studies suggest that even if insoluble substances coat salt particles in the atmosphere, there may be relatively little effect on the resulting water uptake and loss.
\end{abstract}

\section{Introduction}

Atmospheric aerosols are a mixture of many inorganic and organic compounds. It is currently not clear how these combinations of compounds interact to impact the particle growth, the cloud condensation ability of the particle and the

Correspondence to: $\mathrm{M}$. Tolbert

(margaret.tolbert@ colorado.edu) catalytic behavior of the particle towards heterogeneous reactions. The water uptake and loss by ammonium sulfate, a major component of tropospheric aerosol, has been extensively studied in the laboratory. Ammonium sulfate under goes a deliquescence transition at $80 \% \mathrm{RH}$ and an efflorescence transition at $30 \% \mathrm{RH}$ at $273 \mathrm{~K}$ (Tang and Munkelwitz, 1993; Han and Martin, 1999; Onasch et al., 1999). However, field data show that atmospheric sulfate particles may contain $50 \%$ or more organic material by mass (Saxena and Hildemann, 1996; Middlebrook et al., 1998; Murphy et al., 1998). Several recent water uptake and loss studies of mixed inorganic and water-soluble organics have been reported (Cruz and Pandis, 2000; Peng et al., 2001; Choi and Chan, 2002; Brooks et al., 2003; Prenni et al., 2003; Wise et al., 2003; Xu et al., 2003; Braban and Abbatt, 2004; Marcolli et al., 2004; Pant et al., 2004; Parsons et al., 2004). Generally these studies have shown that the addition of water-soluble organic compounds decreases the deliquescence relative humidity. This effect would be predicted using the Gibbs-Duhem equation (Wexler and Seinfeld, 1991) and follows the modeling of multicomponent deliquescence (Nenes et al., 1998; Clegg et al., 2001). However, recent fieldwork has shown that much of the organic matter present in atmospheric aerosols is water insoluble (Cecinato et al., 2000; Gelencser et al., 2000; Graham et al., 2003; Tervahattu et al., 2005).

The impact of insoluble organics on the properties of ammonium sulfate is much less well characterized than that of water-soluble organics. Fatty acids such as myristic acid, stearic acid and palmitic acid form an important class of insoluble organics found at the surface of marine aerosols (Mochida et al., 2002; Russell et al., 2002; Tervahattu et al., 2002; Tervahattu et al., 2002; Mochida et al., 2003) and forest fire aerosols (Peterson and Tyler, 2003). Therefore, it is possible that these compounds form a hydrophobic coating with their hydrophilic carboxyl groups buried in the aerosol's core; thereby leaving the surface of the aerosol hydrophobic and possibly impacting water uptake (Gill et al., 1983;

(C) 2005 Author(s). This work is licensed under a Creative Commons License. 


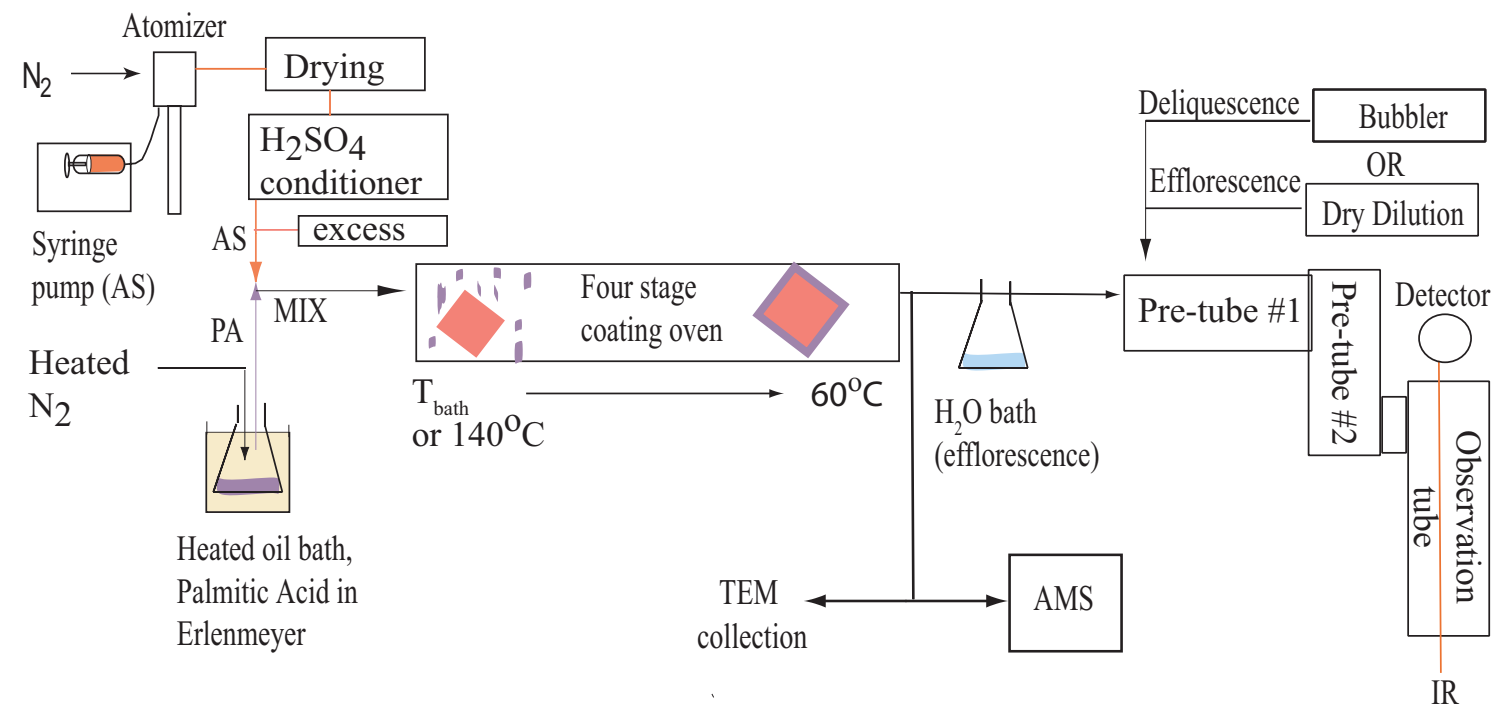

Fig. 1. Experimental set-up. Aerosols are produced and then sent to either the flowtube system for FTIR analysis or the Aerosol Mass Spectrometer for chemical and size analysis. For TEM analysis the particles are collected after they exit the oven.

Ellison et al., 1999). While recent observations have shown the prevalence of water insoluble compounds in atmospheric particles, there is still little information on how water insoluble organics impact phase changes of the salt aerosols.

Organic coatings can potentially affect aerosols in several ways. Studies have shown that the presence of a surface active organic on ammonium sulfate and ammonium nitrate aerosols will decrease water evaporation rates (Shulman et al., 1997; Cruz et al., 2000). Further a coating of surface active organics can act as a barrier for the reactivity and transport of trace atmospheric gases into the bulk aerosol (Niessner, 1984; Daumer et al., 1992; Folkers et al., 2003). However, the effect of the coatings on water uptake and phase changes is not clear. Some studies have found that a coating does impact deliquescence and water uptake (Andrews and Larson, 1993; Xiong et al., 1998; Chen and Lee, 1999; Chen and Lee, 2001) while other studies have seen minor (Hansson et al., 1998) or no changes (Wagner et al., 1996).

In this study, we produce and characterize ammonium sulfate particles mixed with different amounts of palmitic acid and study the effect of the organic on the deliquescence and efflorescence relative humidities. Palmitic acid is a water insoluble sixteen carbon n-alkanoic acid that is prevalent in the atmosphere due to its occurrence as a fatty acid in cell membranes. Sources include anthropogenic emissions, such as from fossil fuel burning, meat cooking and fireplaces (Rogge et al., 1993; Rogge et al., 1998; Cecinato et al., 2000), marine emissions (Mochida et al., 2002; Tervahattu et al., 2002) and terrestrial emissions from forests and vascular plants (Gelencser et al., 2000; Pio et al., 2001; Graham et al., 2003) and forest fires (Peterson and Tyler, 2003). Due to palmitic acid's structure with a hydrocarbon hydrophobic tail and a carboxylic acid hydrophilic head, it is a surface active or- ganic (Seidl, 2000). It has been suggested that palmitic acid could form a reverse micelle around a salt core (Ellison et al., 1999). Indeed, field studies have found palmitic acid preferentially on the surface of aerosols (Tervahattu et al., 2002; Peterson and Tyler, 2003). Our study will probe how this palmitic acid affects the deliquescence and efflorescence phase transitions of ammonium sulfate.

\section{Experimental}

A schematic of the aerosol generation system, the flowtube apparatus and the detection system is given in Fig. 1. Pure ammonium sulfate particles were produced using an atomizer (TSI Model 3076) and a syringe pump (Harvard Apparatus 22). These pure particles were then passed through a diffusion dryer and a $96 \mathrm{wt} \% \mathrm{H}_{2} \mathrm{SO}_{4} / 4 \mathrm{wt} \% \mathrm{H}_{2} \mathrm{O}$ bath to lower the relative humidity to $<30 \% \mathrm{RH}$, so that the ammonium sulfate particles would effloresce. Before coating the ammonium sulfate, the particles were passed through the FTIR to check that they were indeed dry. Palmitic acid vapor was produced by passing hot nitrogen gas $\left(\sim 100^{\circ} \mathrm{C}\right)$ over an oil bath containing an Erlenmeyer flask with pure palmitic acid. The oil bath was heated to temperatures in the range 100$140^{\circ} \mathrm{C}$ to vaporize the palmitic acid. The ammonium sulfate particles and palmitic acid vapor were then mixed and entered an in-line oven $(1.17 \mathrm{~m} \times 1.9 \mathrm{~cm})$. The temperature at the entrance of the oven was set to the bath temperature in deliquescence experiments and to $140^{\circ} \mathrm{C}$ in efflorescence experiments. In addition to comparing the pure palmitic mass spectrum with a NIST reference spectrum, ${ }^{1} \mathrm{H}$-NMR spectra were obtained to confirm that the heating of palmitic acid to $140^{\circ} \mathrm{C}$ does not decompose the acid. The temperature in 
the oven was then decreased in four stages to a temperature of $60^{\circ} \mathrm{C}$, a temperature where both ammonium sulfate and palmitic acid are solid. The oven is similar to that in Han and Martin (2001) and has a temperature gradient such that the palmitic acid will not become highly supersaturated and homogenously nucleate, but rather will condense on the ammonium sulfate seed particles. We are assuming that since the particles were produced via condensation of palmitic acid vapor on the ammonium sulfate seed, the organic forms a coating on the ammonium sulfate. However, the surface of the aerosol was not fully characterized and thus the internal mixing state of the aerosols is not known. For discussion purposes, we will assume that the aerosols are indeed coated. Pure palmitic acid particles were generated by the same system without the added ammonium sulfate, i.e. homogeneous nucleation of palmitic acid, at a bath temperature of $140^{\circ} \mathrm{C}$.

Transmission Electron Microscopy (TEM) images of the particles were obtained by impacting dry particles $(\mathrm{RH}<30 \%)$ on carbon-coated TEM grids after exiting the oven. Particles were collected for 1-2 min and then imaged on a Phillips CM10 (FEI Inc Hillsboro, OR) scope. The TEM images were used to obtain information on the morphology of the particles generated using the coating oven.

Additional information on particle size, composition and mixing state was obtained using an Aerodyne Aerosol Mass Spectrometer (AMS; Aerodyne Inc, MA (Jayne et al., 2000; Jimenez et al., 2003)). Particles entering the AMS are preferentially focused over gases by a factor of $\sim 10^{7}$. The particles pass through a particle time of flight (PTOF) region at the end of which they strike a vaporizer $\left(\sim 600^{\circ} \mathrm{C}\right)$. The vaporized molecules enter into the electron impact ionization region, and the positive ions formed are mass analyzed with a quadrupole mass spectrometer. Since ionization occurs under high vacuum, ion-molecule reactions are suppressed and quantitative information on the mass loading at each $\mathrm{m} / \mathrm{z}$ can be obtained. The mass spectrum can then be compared to known fragmentation patterns in order to identify the amount of mass coming from different compounds (i.e. sulfates, organics, nitrates). The organic traces were compared with the NIST reference spectrum for palmitic acid.

In water uptake and loss studies, the particles passed through a temperature-controlled flowtube system. The flowtube consisted of two $80 \mathrm{~cm}$ pre-tubes to equilibrate the aerosols with water and one $80 \mathrm{~cm}$ observation tube equipped with single pass Fourier Transform Infrared (FTIR) Spectroscopy for detection of the particles' phase. The tubes were double jacketed to allow the methanol coolant to circulate throughout and control the temperature of the flowtubes to $273 \mathrm{~K}$. The IR spectra were used to confirm the presence of palmitic acid and ammonium sulfate in the flowtube and to detect the phase transitions.

To perform deliquescence experiments, the coated aerosols were mixed with a humidified nitrogen flow upon entering the flowtubes at $273 \mathrm{~K}$. This humidified flow was produced with a temperature-controlled water bubbler and

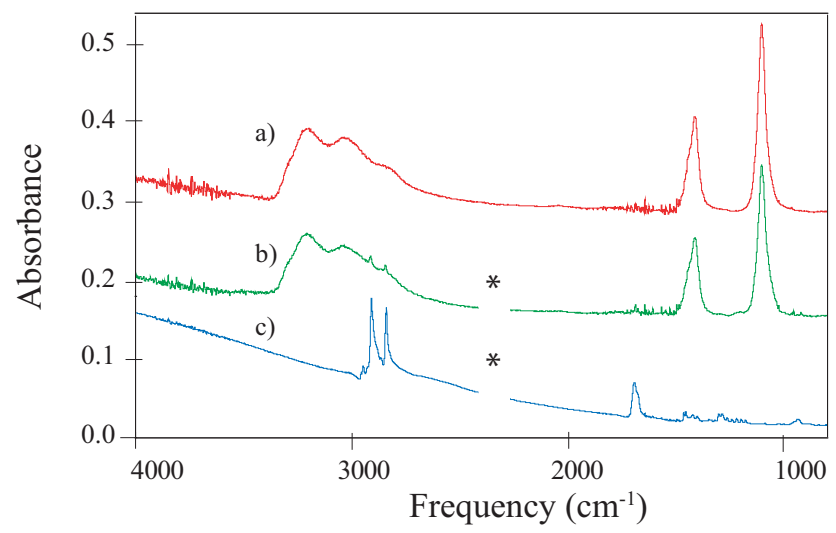

Fig. 2. Representative IR spectra of (a) pure ammonium sulfate; (b) $48.8 \mathrm{wt} \%$ palmitic acid/51.2 wt\% ammonium sulfate and (c) pure palmitic acid; * indicates $\mathrm{CO}_{2}$ absorption bands subtracted out; the bands are an artifact from the coating method.

the flow rate was increased as the experiment progressed, thereby increasing the RH in the tubes. For efflorescence experiments, the mixed aerosols left the oven and were passed over a water bath to deliquesce before entering the flowtubes. A dry dilution flow was added and incrementally increased to lower the RH until the particles were dry. The residence time of the particles in the flowtubes was 1-3 min.

Relative humidity probes (Vaisala, Humitter 50Y) and gas phase water infrared absorption peaks were used to determine relative humidity $(\mathrm{RH})$. A water calibration was performed by passing dry nitrogen gas over ice deposited in the flowtubes at a known temperature. The IR gas phase water peaks were then calibrated to the known water pressure over the ice. Using this calibration, the RH in the flowtubes during an experiment could be determined. Most experiments used the RH probes (uncertainty of $\pm 3 \% \mathrm{RH}$ ) and the ice calibration was used to check the accuracy of the probes. Each experiment has a total error of $\pm 3-5 \% \mathrm{RH}$ due temperature gradients in the flowtubes, the probes' uncertainty and the increments by which the relative humidity was increased.

\section{Results and Discussion}

\subsection{Particle Characterization}

Infrared spectroscopy was used to characterize the mixed aerosol system of ammonium sulfate and palmitic acid as well as to probe the water uptake and loss by the aerosols. Spectra 2a-c show the dry IR spectra of pure ammonium sulfate, mixed ammonium sulfate and palmitic acid (bath $=120^{\circ} \mathrm{C}$ ) and pure palmitic acid (bath $=140^{\circ} \mathrm{C}$ ), respectively. Spectrum $2 \mathrm{a}$ agrees well with the literature spectrum of ammonium sulfate and spectrum $2 \mathrm{c}$ agrees with the literature spectrum of pure palmitic acid. As can be seen in spectrum $2 b$, the IR spectrum of mixed particles exhibits 


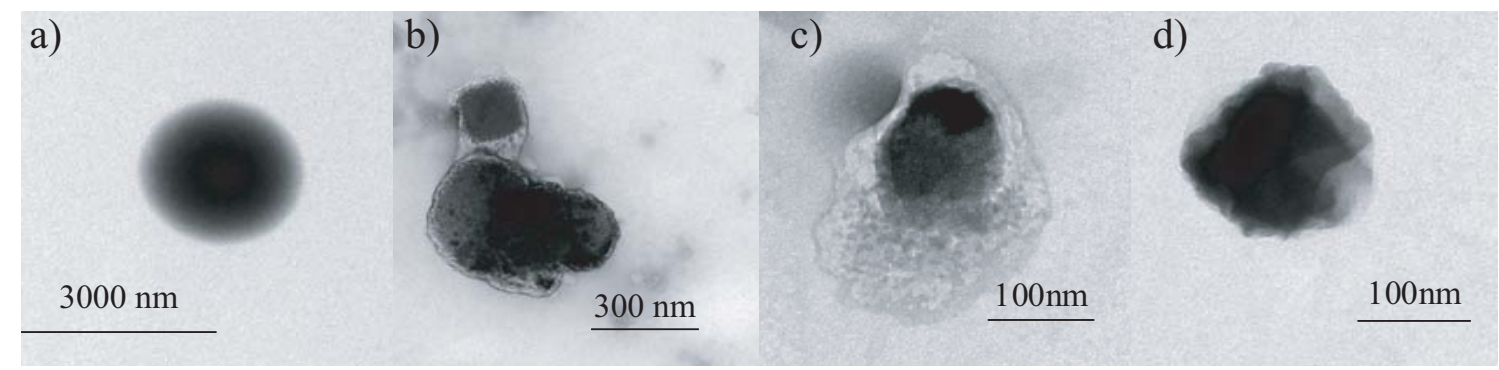

Fig. 3. TEM images of (a) pure palmitic acid; (b) and (c) $\sim 49 \mathrm{wt} \%$ palmitic acid $/ 51 \mathrm{wt} \%$ ammonium sulfate; and (d) pure ammonium sulfate. Note the differences in the size bars.

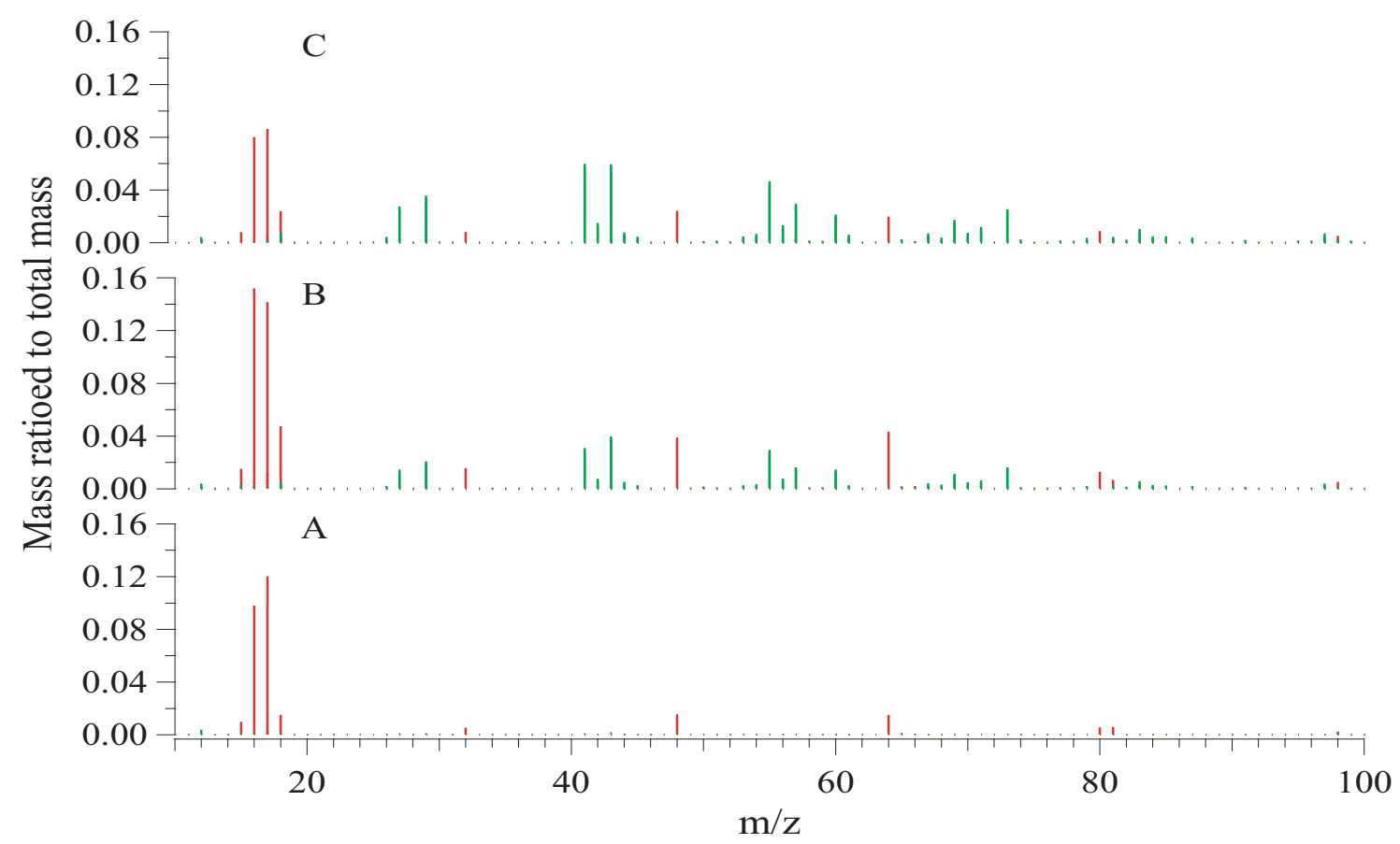

Fig. 4. AMS MS traces of ammonium sulfate/palmitic acid aerosol. The green indicate organic peaks and the red are sulfate peaks, A) pure ammonium sulfate; B) bath set to $120^{\circ} \mathrm{C}$ (internally mixed aerosols that are $48.8 \mathrm{wt} \%$ organic $/ 51.2 \mathrm{wt} \%$ ammonium sulfate); and C) bath set to $140^{\circ} \mathrm{C}$ (partially externally mixed aerosols that have an overall composition of $81 \mathrm{wt} \%$ organic/19 wt $\%$ ammonium sulfate).

features of both pure ammonium sulfate and pure palmitic acid. However, because of overlapping bands, only the C-H stretch of palmitic acid $\left(2937-2840 \mathrm{~cm}^{-1}\right)$ is clearly visible in the mixed aerosol system. While these IR spectra show that both ammonium sulfate and palmitic acid are present in the condensed phase, it cannot be determined from the IR spectra if the two components are internally or externally mixed.

Additional information on the mixing state of the particle was obtained using Transmission Electron Microscopy (TEM). Example TEM images of pure palmitic acid, pure ammonium sulfate and coated ammonium sulfate particles are shown in Fig. 3. Pure ammonium sulfate particles are extremely volatile in the TEM electron beam and thus difficult to image. Before they are destroyed in the beam, how- ever, they are sub-micrometer in size, semi-round and have distinct borders. In contrast, the pure palmitic aerosols are larger than one micrometer, spherical and stable under the electron beam. The large size of the pure palmitic acid particles is also evident in the IR spectrum in spectrum $2 \mathrm{c}$ by the increased scattering signal for wavenumbers greater than $2000 \mathrm{~cm}^{-1}$. The mixed aerosols are more stable in the electron beam than the pure ammonium sulfate, although less stable than the pure palmitic acid. They also appear to have a clear coating surrounding a circular dense particle. Figures $3 \mathrm{~b}$ and $3 \mathrm{c}$ illustrate the range of particle morphologies observed in the TEM for the mixed particles. While these particles look different from each other, they all exhibited similar stability in the electron beam and all showed the presence of a coating. All samples were scanned using a lower 
Table 1. Characterization of palmitic acid (PA) coating.

\begin{tabular}{lcccc}
\hline Bath/oven temp & Wt\% organic* & $\begin{array}{c}\text { Thickness of } \\
\text { org. coating }\end{array}$ & $\begin{array}{c}\text { \# of monolayers } \\
\text { sphere }\end{array}$ & $\begin{array}{c}\text { PA assuming, } \\
\text { cylinder }\end{array}$ \\
\hline $100 / 100^{\circ} \mathrm{C}$ & $18.8 \pm 5.0 \%$ & $21.2 \mathrm{~nm}$ & 129 & 9 \\
$120 / 120^{\circ} \mathrm{C}$ & $48.8 \pm 3.3 \%$ & $89.1 \mathrm{~nm}$ & 543 & 36 \\
$100-120 / 140^{\circ} \mathrm{C}$ & $43.5 \pm 6.7 \%$ & $65.3 \mathrm{~nm}$ & 398 & 26 \\
\hline
\end{tabular}

*The remaining mass is ammonium sulfate

intensity of the electron beam before imaging to view the whole sample for irregularities; at these intensities, the ammonium sulfate particles were stable. This combination of characteristics in the mixed aerosol leads us to believe that most or all of the ammonium sulfate particles were indeed coated with palmitic acid.

We also can gain information on the composition and mixing state of the aerosol using the AMS. The AMS has a particle time of flight (PTOF) section and a quadrupole, allowing for simultaneous measurement of size and chemical composition of aerosols. Figure 4a shows the mass spectrometer trace for pure ammonium sulfate aerosols. The only peaks visible are those that can be attributed to ammonium sulfate. Figures $4 \mathrm{~b}$ and $4 \mathrm{c}$ display mass spectrometer traces for the mixed particles as a function of oven temperature. When the bath temperature is $120^{\circ} \mathrm{C}$, Fig. $4 \mathrm{~b}$, the mass spectrograph contains both ammonium sulfate peaks and those attributed to organics. The organic peaks increase when the bath temperature reaches $140^{\circ} \mathrm{C}$ as in Fig. $4 \mathrm{c}$, illustrating that the amount of palmitic acid in the particles can be controlled by the bath temperature. The organic traces match with the NIST reference spectrum for palmitic acid; including the presence of the molecular ion at $\mathrm{m} / \mathrm{z} 256$. The TOF size distributions accompanying the mass spectra are shown in Fig. 5. Main sulfate peaks $(\mathrm{m} / \mathrm{z} 48$ and 64), ammonium peaks $(\mathrm{m} / \mathrm{z}, 16)$ and organic peaks $(\mathrm{m} / \mathrm{z}, 43$ and 55$)$ were used to measure the size distribution of the aerosols. It can be seen that at the lower temperature, Fig. 5a, the coating procedure created particles where both the organic and the sulfate fragments covered the entire size distribution. This is an indication of internally mixed particles. In contrast, at higher bath temperatures, Fig. 5b, the bath created separate populations where the smaller ammonium sulfate aerosols do not appear to have a significant organic component and the large palmitic acid particles contain a lower fraction of sulfate. In this case, a partially externally mixed aerosol is likely present. Thus, bath temperatures used for this study were $120^{\circ} \mathrm{C}$ and below to insure internally mixed aerosols.

Using the size distributions from the AMS, the average organic weight percent for each temperature was calculated and the values are shown in Table 1 . The $100^{\circ} \mathrm{C}$ bath creates aerosols that are $\sim 20 \mathrm{wt} \%$ palmitic acid and $\sim 80 \mathrm{wt} \%$ ammonium sulfate while the $120^{\circ} \mathrm{C}$ bath creates particles that are $\sim 49 \mathrm{wt} \%$ palmitic acid and $\sim 51 \mathrm{wt} \%$ ammonium sul-
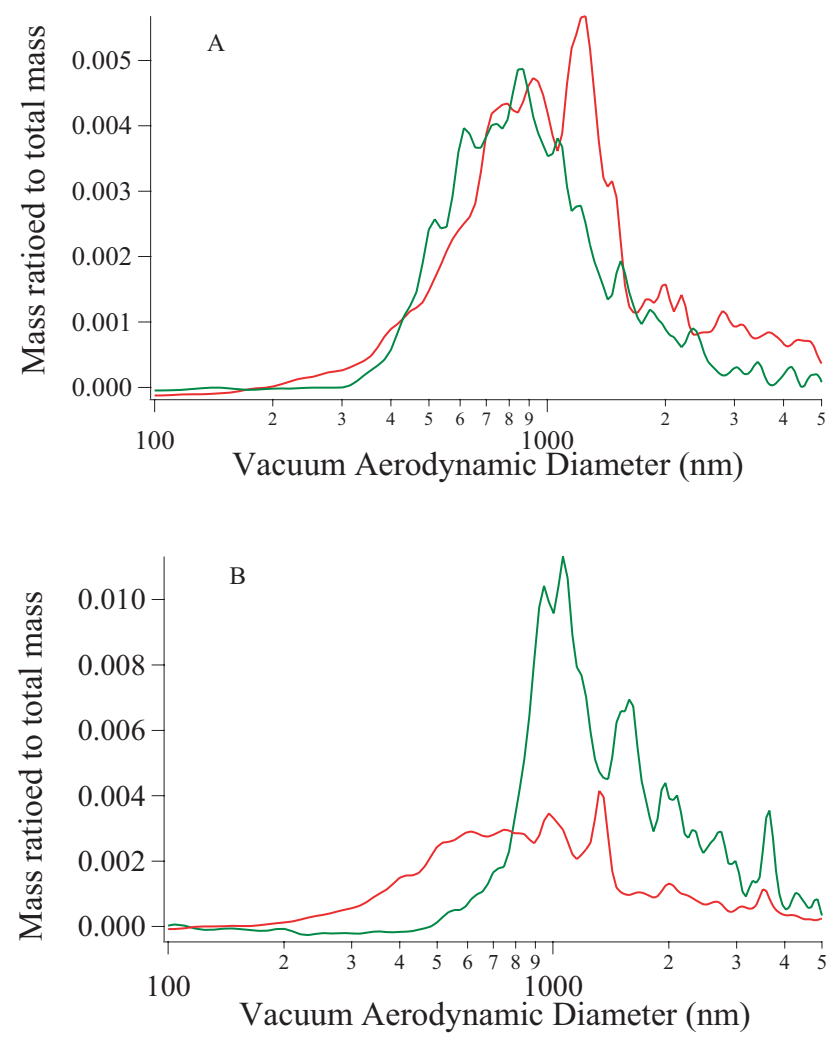

Fig. 5. TOF size distributions of A) palmitic acid bath at $120^{\circ} \mathrm{C}$ producing internally mixed aerosols with a composition of $48.8 \mathrm{wt} \%$ organic $/ 51.2 \mathrm{wt} \%$ ammonium sulfate and $\mathrm{B}$ ) bath at $140^{\circ} \mathrm{C}$ producing a partially externally mixed aerosol population. The red is the ammonium sulfate trace and the green line is the organic trace.

fate. Deliquescence experiments were performed on both of these compositions. Efflorescence experiments were conducted on $\sim 44 \mathrm{wt} \%$ palmitic acid and $\sim 56 \mathrm{wt} \%$ ammonium sulfate aerosols.

The weight percent organic determined from the AMS data was then converted into an average thickness of palmitic acid, assuming the palmitic acid existed as a shell around the ammonium sulfate. This is an approximate average thickness, as the distributions are very polydisperse. The particle volume was calculated by first converting the mean vacuum aerodynamic diameter $\left(d_{v a}\right)$ from the AMS mass distribution to the volume equivalent diameter by dividing by the particle density and assuming spherical particles (DeCarlo et al., 2004). Using this diameter, the volume of the particle was calculated. This total volume was translated into a total mass using the calculated density of the particle obtained from the weight percent organic and ammonium sulfate assuming volume additivity of the inorganic and organic phases. The volume of the ammonium sulfate seed was calculated from this total mass, using the density of ammonium sulfate and the weight percent from the AMS. The difference between the total volume and the ammonium sulfate volume was used 

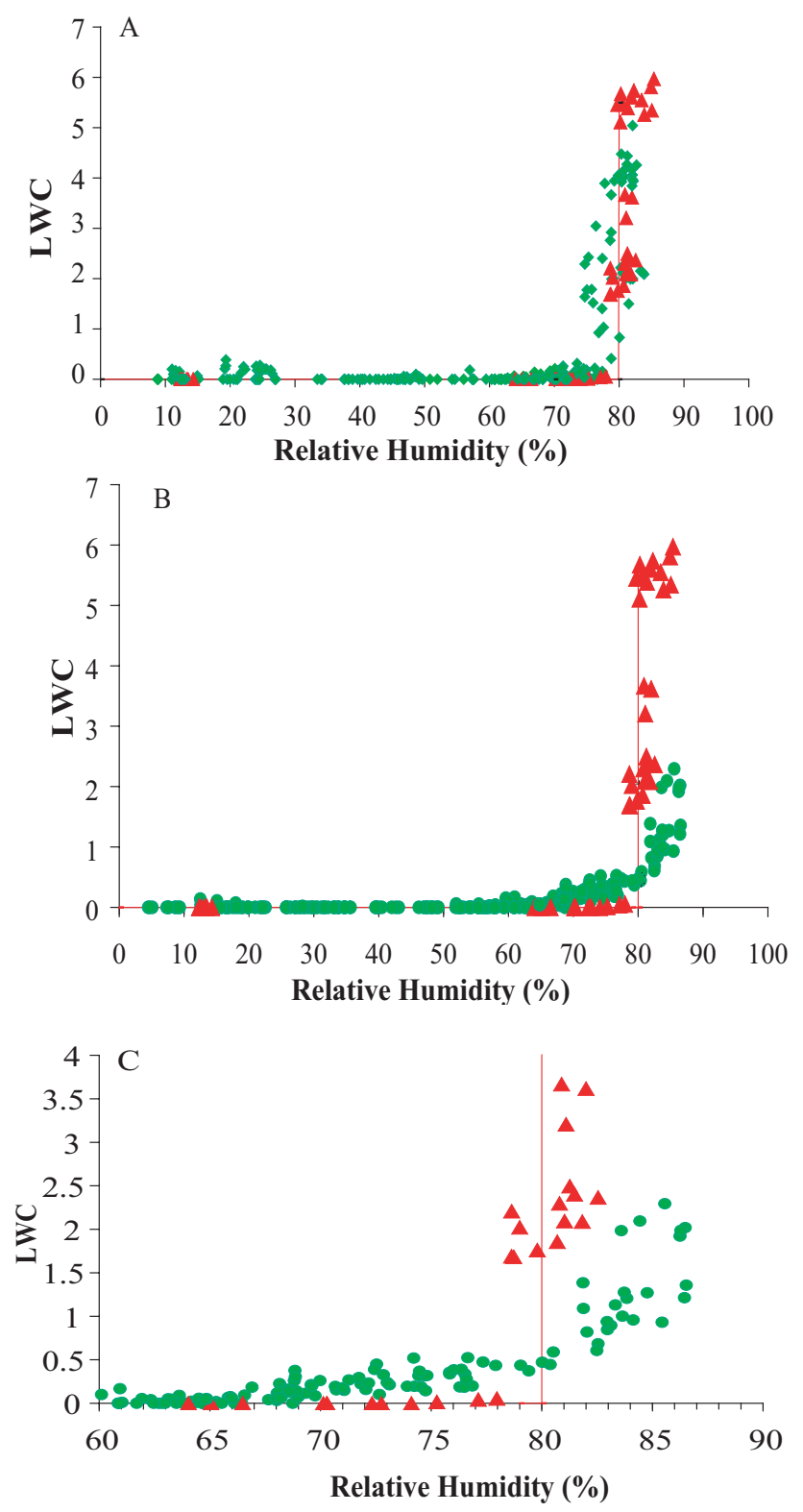

Fig. 6. Deliquescence of mixed ammonium sulfate/palmitic acid particles at $273 \mathrm{~K}$. Red triangles are pure ammonium sulfate; line indicates where pure ammonium sulfate deliquesces. A) $18.8 \mathrm{wt} \%$ organic as green diamonds; B) $48.8 \mathrm{wt} \%$ organic as green circles; C) expanded view of graph B to show early water uptake by $48.8 \mathrm{wt} \%$ organic aerosols.

to estimate the radial thickness of the coating. The calculated coating thicknesses are summarized in Table 1. Deliquescence experiments were performed on aerosols with two different thicknesses, $21 \mathrm{~nm}$ and $89 \mathrm{~nm}$, while efflorescence experiments were performed on aerosols with a palmitic acid thickness of $65 \mathrm{~nm}$. Finally, the number of monolayers of palmitic acid for each case was estimated using the density of palmitic acid $\left(0.8527 \mathrm{~g} / \mathrm{cm}^{3}\right)$ to calculate a monolayer cov- erage of $3.285 \times 10^{13}$ molecules $/ \mathrm{cm}^{2}$ assuming palmitic acid acts as a sphere and $5.006 \times 10^{14}$ molecules $/ \mathrm{cm}^{2}$ if it acts as a cylinder, where the length of the cylinder is the carbon chain and the face of the cylinder is the carboxyl group. The latter method of calculating the monolayer coverage is in good agreement with the values for stearic acid, an 18-carbon carboxylic acid that would be expected to have similar values (Gilman et al., 2004). The number of monolayers was calculated using this monolayer coverage and the thickness calculated above. In all three cases, it can be seen that the palmitic acid coating was much greater than monolayer coverage. Due to this, we inferred that the palmitic acid coating would not be in a simple micelle arrangement, but rather a more complex system with possible surface defects and both hydrophobic and hydrophilic areas.

While none of the above techniques alone prove that we have successfully coated the ammonium sulfate particles, the techniques together all make a stronger case that the mixed particles generated contain palmitic acid and ammonium sulfate, and that the palmitic acid forms a coating on the ammonium sulfate.

\subsection{Water uptake and loss}

After characterizing the particles, studies were performed to determine how ammonium sulfate particles coated with palmitic acid responded to increases and decreases in water vapor. In these studies, the liquid water content of the aerosols was determined using FTIR transmission spectroscopy. For pure ammonium sulfate and the mixed aerosol experiments, the ratio of a condensed phase water peak $\left(3586-3358 \mathrm{~cm}^{-1}\right)$ to a sulfate peak $\left(1180-999 \mathrm{~cm}^{-1}\right)$ was defined to be the liquid water content (LWC) of the aerosol. These two IR peaks were ratioed to account for dilution of the aerosols throughout the experiment. LWC, as a ratio, has no units and is thus only a qualitative measure of the amount of water in the aerosol and not a growth factor. Only experiments ratioing the same peaks can be directly compared. Figure 6a shows the deliquescence curves for pure ammonium sulfate and $\sim 20 \mathrm{wt} \%$ palmitic acid $/ 80 \mathrm{wt} \%$ ammonium sulfate as a function of relative humidity (RH). The solid line indicates the deliquescence relative humidity (DRH) of pure ammonium sulfate at $80 \% \mathrm{RH}$. Note that there is little difference between the curves as the mixed aerosol also has a DRH of approximately $80 \%$. At the deliquescence point, they both acquire a similar liquid water content.

Figure $6 \mathrm{~b}$ displays the deliquescence of pure ammonium sulfate and $\sim 50 \mathrm{wt} \%$ palmitic acid $/ 50 \mathrm{wt} \%$ ammonium sulfate. With this thicker coating of palmitic acid, a change in water uptake is noted. First, there is no clear deliquescence point with the mixed aerosol within the range of $\mathrm{RH}$ probed. While ammonium sulfate has a clear vertical transition at $80 \% \mathrm{RH}$ the mixed aerosol shows a more continuous water uptake with increasing relative humidity. In addition, above $80 \%$ RH water uptake after deliquescence for the pure 


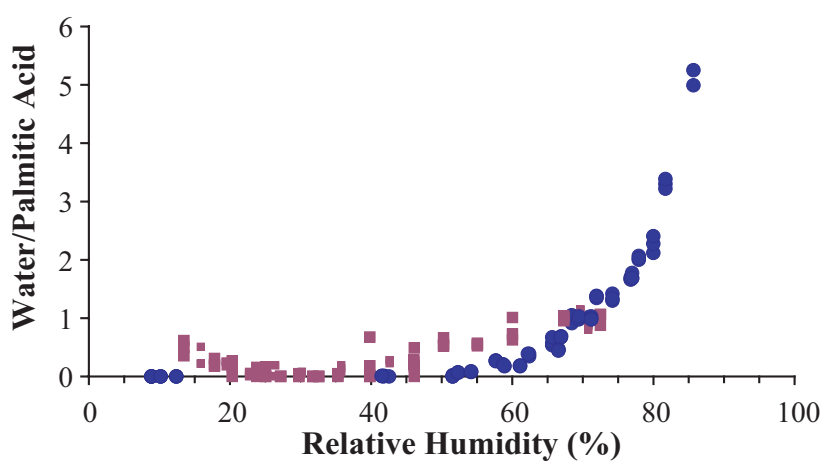

Fig. 7. Deliquescence (blue circles) and efflorescence (purple squares) experiments for pure palmitic acid at $273 \mathrm{~K}$. Note there are no clear transitions indicating that deliquescence or efflorescence occurs.

ammonium sulfate can be seen by a change in growth with relative humidity. In contrast, for the mixed case this change in growth was not observed. Without seeing these signatures, we are unable to clearly label a DRH for the $50 \mathrm{wt} \%$ organic case. Finally, as illustrated in Fig. 6c, an expanded view of the $50 \mathrm{wt} \%$ organic aerosol, there is water uptake before $80 \%$ RH in the mixed aerosol that is not seen in pure ammonium sulfate. At $\sim 69 \% \mathrm{RH}$ the mixed aerosol particles begin to show an increase in LWC that continues to $85 \% \mathrm{RH}$, at which relative humidity the mixed aerosol has less than $40 \%$ the liquid water content than the pure ammonium sulfate. It cannot be determined if this decrease in water uptake would still occur if the particles were exposed to the humidified flow for more than $\sim 3$ minutes, which is the longest residence time available in the flowtube apparatus.

Pure palmitic acid has a solubility of $0.0007 \mathrm{~g} / 100 \mathrm{~mL}$ $\mathrm{H}_{2} \mathrm{O}$ (Yaws, 1999) and thus would be considered a nondeliquescent material. Figure 7 displays the results for deliquescence and efflorescence experiments of pure palmitic acid. In the pure palmitic case, the liquid water band integrated was the same as above $\left(3586-3358 \mathrm{~cm}^{-1}\right)$. This water peak, however, was ratioed to a palmitic acid absorbance band $\left(2937-2861 \mathrm{~cm}^{-1}\right)$. Thus, the y-axis of the pure palmitic case and the rest of the experiments cannot be directly compared. It does not appear that palmitic acid actually deliquesces, as there is no hysterisis seen in the efflorescence experiments. Rather than deliquescence, we are more likely measuring water adsorbing to the surface of the particle. Figure 7 also shows the efflorescence results for pure palmitic acid. Within experimental uncertainty, the efflorescence and deliquescence curves overlap and there is no hysterisis. Again, this is consistent with a non-deliquescent material that only takes up a small amount of water.

To crudely compare deliquescence experiments of the mixed aerosols to the pure organic aerosols, the data for $50 \mathrm{wt} \%$ palmitic acid was reanalyzed by subtracting out the ammonium sulfate peaks and then taking the ratio of the wa-

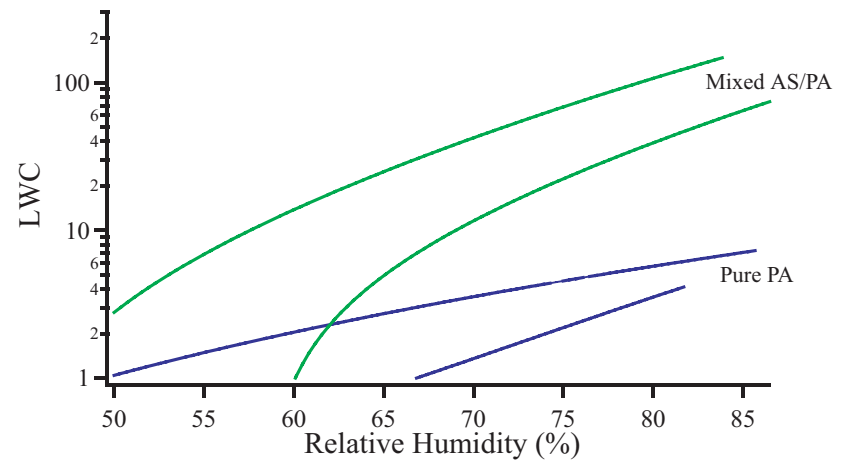

Fig. 8. Mixed palmitic acid $(50 \mathrm{wt} \%)$ and ammonium sulfate (50 wt $\%$ ) aerosols (green lines) and pure palmitic acid aerosols (blue lines) using same palmitic acid and condensed water peaks to calculate the liquid water content (LWC). The two lines represent the outer limits of the data; thus all the data lies between the two lines.

ter peak to the palmitic acid peak used above. The comparison between the water uptake of the mixed and pure palmitic acid aerosols can be seen in Fig. 8 on a logarithmic scale. The outer limits of the data are represented by the two lines, as the absolute numbers are difficult to compare because the spectral subtraction produces significant noise. Compared to the mixed aerosols, the pure palmitic acid particles are observed to take up much less water. However, this figure illustrates that throughout a deliquescence experiment the mixed aerosols tend to follow roughly the same uptake curve as the palmitic acid. This suggests that the palmitic acid coating dictates water uptake prior to deliquescence. The difference in magnitude before $80 \% \mathrm{RH}$ of the mixed aerosols to the pure aerosols may be due to a difference in the surface structures of the two aerosol types. However, this cannot be elucidated from our findings. Differences in magnitude after $80 \%$ RH are most likely due to the ammonium sulfate core.

Efflorescence experiments were also conducted on pure ammonium sulfate and on the higher weight percent organic mixed aerosol. Figure 9 displays the efflorescence data for pure ammonium sulfate and $\sim 45 \mathrm{wt} \%$ palmitic acid $/ 55 \mathrm{wt} \%$ ammonium sulfate aerosols. Ammonium sulfate has an efflorescence relative humidity of $\sim 31 \% \mathrm{RH}$ (Cziczo and Abbatt, 1999; Onasch et al., 1999) and here we find that the mixed case has an identical efflorescence relative humidity within experimental error. Even this very large coating does not seem to impact the efflorescence relative humidity. Thus, we can assume that a coating of palmitic acid does not change the crystallization of ammonium sulfate under most atmospherically realistic loadings of insoluble organics.

\section{Conclusions and Atmospheric Implications}

The results of our FTIR water uptake study show that the addition of a coating that is $\sim 50 \mathrm{wt} \%$ water insoluble organic 


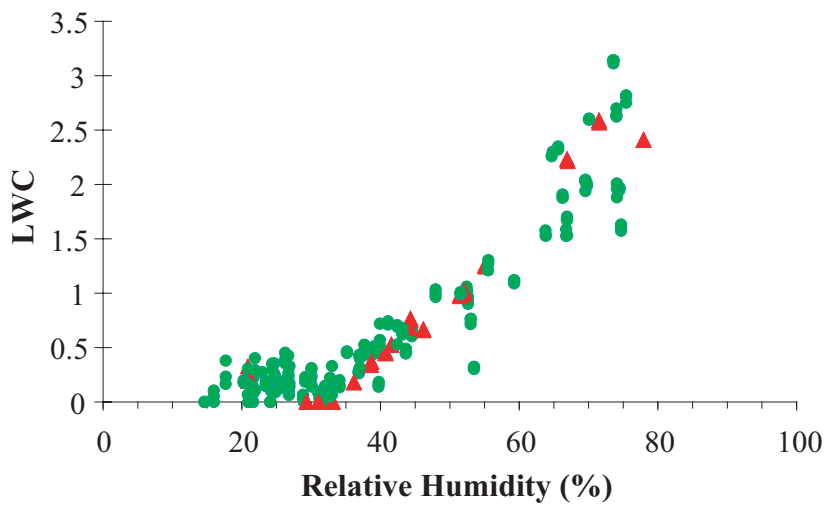

Fig. 9. Efflorescence of pure ammonium sulfate (red triangles) and $43.5 \mathrm{wt} \%$ palmitic acid (green circles).

does not impact the efflorescence of ammonium sulfate and only slightly changes the water uptake of the aerosol, while a thinner coating appears to have no discernable effect. As the concentration of fatty acids in atmospheric aerosols are thought to be much lower than the particles generated here, usually on the order of a monolayer of coverage on the aerosols (Gill et al., 1983; Middlebrook et al., 1998; Ellison et al., 1999; Fang et al., 1999; Mochida et al., 2002; Graham et al., 2003; Tervahattu et al., 2005), this experiment indicates that a thin coating will not change the water uptake of ammonium sulfate particles greatly, although a thicker coating may.

Again, neither a DRH nor a water uptake curve can be determined for the $\sim 50 \mathrm{wt} \%$ organic $/ 50 \mathrm{wt} \%$ ammonium sulfate particles from our data. If the particles have indeed stopped growing, then the DRH changes little and the water uptake changes greatly, while if the particles are still growing they may still take up as much water as pure ammonium sulfate particles. This cannot be resolved in the flowtube apparatus as the residence time is fixed at $<3 \mathrm{~min}$. It has been suggested that the deliquescence relative humidity (DRH) and efflorescence relative humidity (ERH) will not change with the addition of a coating, but rather the timescale for water uptake will change (Barnes, 1986; Chuang, 2003). Many studies have found that while the DRH did not change, the growth rate decreased dramatically, with a particle taking up to $90 \mathrm{~min}$ to fully deliquesce (Andrews and Larson, 1993; Wagner et al., 1996; Chen and Lee, 1999). If a change in growth rate were to occur in our experiment, it could have a large impact on the aerosols ability to act as efficient cloud condensation nuclei.

The efflorescence results suggest that the palmitic acid coating is not acting as heterogeneous nuclei for the ammonium sulfate. If palmitic acid were acting as a heterogeneous nucleus we would expect to see an increase in efflorescence relative humidity, similar to that of solid inclusions in ammonium sulfate aerosols (Han and Martin, 1999; Martin et al., 2001). Rather, the palmitic acid does not change the crystallization of ammonium sulfate.
The adsorption of water at lower relative humidities indicates that aerosols with a coating may contain water under a wider range of relative humidities than pure inorganic salts. Previous studies on the cloud condensation nuclei (CCN) activation of ammonium sulfate coated with water insoluble dioctylphthalate (Cruz and Pandis, 1998) as well as sodium chloride and ammonium sulfate coated with water insoluble hexadecane (Raymond and Pandis, 2003) have shown that there is no observable effect on CCN ability by the coatings. These water insoluble compounds themselves are not CCN active, but apparently have no measurable impact on the salt activation. This is similar to our observations that although palmitic acid is not hygroscopic, a coating of it does not appear to hinder water uptake by the ammonium sulfate. However, further studies are needed to probe the impact of various film forming compounds on CCN ability.

It is not clear why the coatings are ineffective in reducing water uptake. It is likely due to either their structural arrangement around the ammonium sulfate or that a full coating was not formed. Molecules such as palmitic acid that normally form reverse micelles around a hydrophilic core have been shown to have the hydrophobic tails collapse onto each other under vacuum (Tobias and Klein, 1996; Allen et al., 2000). Such an arrangement would form many surface defects and pockets. While we are not running experiments in vacuum, we are producing an environment on the aerosol where single monolayer coverage is not possible, and thus a simple micelle is not possible either. In contrast, recent thermodynamic modeling results suggest that compounds such as palmitic acid do not form an inverted micelle that coats the aerosol, but rather pockets of micelles within the aerosol (Tabazadeh, 2005). However, we were not able to characterize the surface of our aerosols, and thus cannot determine what form the palmitic acid took in the aerosol.

Experimental studies of water uptake by hydrophobic surfaces suggest that water uptake does indeed occur on these surfaces, preferentially on the defect sites (Weingartner et al., 1997; Thomas et al., 1999; Rudich et al., 2000; Linderoth et al., 2003; Persiantseva et al., 2004). These studies suggest the water adsorption on these irregularities of the surface are reversible and adsorb through small water clusters. The reversible nature of the water uptake was seen in the pure palmitic acid aerosols, and while it is not possible to know how the water adsorbed to the surface, the total amount of water adsorbed is small. However, if a small amount of water does adsorb to the surface, it can then diffuse through the coating or through coating defects and activate the inorganic core, leading to no difference in water uptake. In such a case the water uptake and loss would be dictated by diffusion through the coating layer only. In order for the water to diffuse through a coating of $100 \mathrm{~nm}$ in the time allowed in our flowtubes, the diffusion constant of water in the coating would have to be at least $5 \times 10^{-13} \mathrm{~cm}^{2} / \mathrm{sec}$; similar to that of a solid. As this diffusion constant is only a lower limit, it suggests that even as an obstacle to water diffusion through 
to the inorganic core, a full coating would have little impact on water uptake.

Acknowledgements. We thank T. Giddings for use of the TEM. This research was supported by the Office of Science (BER), U.S Department of Energy, Grant No. DE-FG02-01ER63096.

Edited by: Y. Rudich

\section{References}

Allen, R., Bandyopadhyay, S., and Klein, M.: C12E2 reverse micelle: A molecular dynamics study, Langmuir, 16, $10547-$ $10552,2000$.

Andrews, E. and Larson, S. M.: Effect of surfactant layers on the size changes of aerosol particles as a function of relative humidity, Environ. Sci. and Tech., 27, 857-865, 1993.

Barnes, G.: The effects of monolayers on the evaporation of liquids, Adv. Colloid Interface Sci., 25, 89-200, 1986.

Braban, C. F. and Abbatt, J. P. D.: A study of the phase transition behavior of internally mixed ammonium sulfate-malonic acid aerosols, Atmos. Chem. Phys., 4, 1451-1459, 2004,

\section{SRef-ID: 1680-7324/acp/2004-4-1451.}

Brooks, S. D., Garland, R. M., Wise, M. E., Prenni, A. J., Cushing, M., Hewitt, E., and Tolbert, M. A.: Phase changes in internally mixed maleic acid/ammonium sulfate aerosols, J. Geophys. Res., 108, D15, 4487, doi:10.1029/2002JD003204, 2003.

Cecinato, A., Mabilia, R., and Marino, F.: Relevant organic components in ambient particulate matter collected at Svalbard Islands (Norway), Atmos. Environ., 34, 29-30: 5061-5066, 2000.

Chen, Y.-Y. and Lee, W.-M. G.: Hygroscopic properties of inorganic-salt aerosol with surface-active organic compounds, Chemosphere, 38, 10, 2431-2448, 1999.

Chen, Y.-Y. and Lee, W.-M. G.: The effect of surfactants on the deliquescence of sodium chloride, J. Environ. Sci. Health, A36, 2, 229-242, 2001.

Choi, M. Y. and Chan, C. K.: The effects of organic species on the hygroscopic behaviors of inorganic aerosols, Environ. Sci. and Tech., 36, 2422-2428, 2002.

Chuang, P. Y.: Measurement of the timescale of hygroscopic growth for atmospheric aerosols, Journal of Geophysical ResearchAtmospheres, 108, D9, 2003.

Clegg, S., Seinfeld, J., and Brimblecombe, P.: Thermodynamic modeling of aqueous aerosols containing electrolytes and dissolved organic compounds, J. Aeros. Sci, 32, 6, 713-738, 2001.

Cruz, C. N., Dassios, K. G., and Pandis, S. N.: The effect of dioctyl phthalate films on the ammonium nitrate aerosol evaporation rate, Atmos. Environ., 34, 23, 3897-3905, 2000.

Cruz, C. N. and Pandis, S. N.: The effect of organic coatings on the cloud condensation nuclei activation of inorganic atmospheric aerosol, J. Geophys. Res., 103, D11, 13 111-13 123, 1998.

Cruz, C. N. and Pandis, S. N.: Deliquescence and Hygroscopic growth of mixed inorganic-organic atmospheric aerosol, Environ. Sci. Technol., 34, 4313-4319, 2000.

Cziczo, D. J. and Abbatt, J. P. D.: Deliquescence, efflorescence, and supercooling of ammonium sulfate aerosol at low temperature: Implications for cirrus cloud formation and aerosol phase in the environment, J. Geophys. Res., 104, D11, 13 781-13 790, 1999.
Daumer, B., Niessner, R., and Klockow, D.: Laboratory studies of the influence of thin organic films on the neutralization reaction of $\mathrm{H} 2 \mathrm{SO} 4$ aerosol with ammonia, J. Aeros. Sci, 23, 4, 315-325, 1992.

Ellison, G., Tuck, A., and Vaida, V.: Atmospheric processing of organic aerosols, J. Geophys. Res., 104, D9, 11 633-11 641, 1999.

Fang, M., Zheng, M., Wang, F., To, K., Jaafar, A., and Tong, S.: The solvent-extractable organic compounds in the Indonesia biomass burning aerosols-Characterization studies, Atmospheric Environment, 33, 5, 783-795, 1999.

Folkers, M., Mentel, T. F. , and Wahner, A.: Influence of an organic coating on the reactivity of aqueous aerosols probed by the heterogeneous hydrolysis of N2O5, Geophys. Res. Lett., 30, 12, 1644, doi:10.1029/2003GL017168, 2003.

Gelencser, A., Meszaros, T., Blazso, M. Kiss, G., Krivacsy, Z., Molnar, A., and Meszaros, E.: Structural characterisation of organic matter in fine tropospheric aerosol by pyrolysis-gas chromatography-mass spectrometry, J. Atmos. Sci., 37, 173$183,2000$.

Gill, P. S., Graedel, T. E., and Weschler, C. J.: Organic films on atmospheric aerosol particles, fog droplets, cloud droplets, raindrops and snowflakes, Reviews of Geophysics and Space Physics, 21, 4, 903-920, 1983.

Gilman, J. B., Eliason, T. L., Fast, A., and Vaida, V.: Selectivity and stability of organic films at the air-aqueous interface, Journal of Colloid and Interface Science, 280, 234-243, 2004.

Graham, B., Guyon, P., Taylor, P., Artaxo, P., Maenhaut, W., Glovsky, M., Flagan, R., and Andreae, M.: Organic compounds present in the natural Amazonian aerosol: Characterization by gas chromatography-mass spectrometry, J. Geophys. Res., 108, D4766, doi:10.1029/2003JD003990, 2003.

Han, J. and Martin, S.: Heterogeneous nucleation of the efflorescence of (NH4)2SO4 particles internally mixed with $\mathrm{Al} 2 \mathrm{O} 3$, TiO2, and ZrO2, J. Geophys. Res., 104, D3, 3543-3553, 1999.

Han, J. H. and Martin, S. T.: An aerosol chemical reactor for coating metal oxide particles with (NH4)SO4-H2SO4-H2O.1. - New particle formation, Aerosol Sci and Tech, 34, 4, 363-372, 2001.

Hansson, H.-C., Rood, M. J., Koloutsou-Vakakis, S., Hämeri, K., Orsini, D., and Wiedensohler, A.: $\mathrm{NaCl}$ aerosol particle hygroscopicity dependence on mixing with organic compounds, J. Atmos. Chem., 31, 321-346, 1998.

Jayne, J., Leard, D., Zhang, X., Davidovits, P., Smith, K., Kolb, C., and Worsnop, D.: Development of an aerosol mass spectrometer for size and composition analysis of submicron particles, Aerosol Sci and Tech, 33, 49-70, 2000.

Jimenez, J. L., Jayne, J. T., Shi, Q., Kolb, C. E., Worsnop, D. R., Yourshaw, I., Seinfeld, J. H., Flagan, R. C., Zhang, X. F., Smith, K. A., Morris, J. W., and Davidovits, P.: Ambient aerosol sampling using the Aerodyne Aerosol Mass Spectrometer, J. Geophys. Res.-A., 108, D7, 8424, doi:10.1029/2001JD000660, 2003.

Linderoth, T. R., Zhdanov, V. P., and Kasemo, B.: Water condensation kinetics on a hydrophobic surface, Phys Rev L, 90, 15, 2003.

Marcolli, C., Luo, B. P., and Peter, T.: Mixing of the organic aerosol fractions: Liquids as the thermodynamically stable phases, Journal of Physical Chemistry A, 108, 12, 2216-2224, 2004. 
Martin, S., Han, J., and Hung, H.: The size effect of hematite and corundum inclusion on the efflorescence relative humidities of aqueous ammonium sulfate particles, Geophys. Res. Lett., 28, 13, doi:10.1029/2001GL013120, 2691-2694, 2001.

Middlebrook, A. M., Murphy, D. M., and Thomson, D. S.: Observations of organic material in individual marine particles at Cape Grim during the First Aerosol Characterization Experiment (ACE 1), J. Geophys. Res., 103, D13, 16475-16483, 1998.

Mochida, M., Kawamura, K., Umemoto, N., Kobayashi, M., Matsunaga, S., Lim, H.-J., Turpin, B., Bates, T. and Simoneit, B.: Spatial distribution of oxygenated organic compounds (dicarboxylic acids, fatty acids, and levoglucosan) in marine environments over the western Pacific and off the coast of East Asia: Continental outflow of organic aerosols during the ACE-Asia campaign, J. Geophys. Res., 108, D23, 2003.

Mochida, M., Kitamore, Y., Kawamura, K., Nojiri, Y., and Suzuki, K.: Fatty acids in the marine atmosphere: Factors governing their concentration and evaluation of organic films on sea-salt particles, J. Geophys. Res., 107, 4325, doi 10.1029/2001JD001278, 2002.

Murphy, D. M., Thomson, D. S., and Mahoney, M. J.: In situ measurements of organics, meteoritic material, mercury, and other elements in aerosols at 5 to 19 kilometers, Science, 282, 5394, 1664-1669, 1998.

Nenes, A., Pandis, S., and Pilinis, C.: ISORROPIA: A new thermodynamic equilibrium model for multiphase multicomponent inorganic aerosols, Aquatic Geochemistry, 4, 123-152, 1998.

Niessner, R.: Coated particles: preliminary results of laboratory studies on interaction of ammonia with coated sulfuric acid droplets or hydrogensulfate particles, The Science of the Total Environment, 36, 353-362, 1984.

Onasch, T. B., Siefert, R. L., Brooks, S. D., Prenni, A. J., Murray, B., Wilson, M. A., and Tolbert, M. A.: Infrared spectroscopic study of the deliquescence and efflorescence of ammonium sulfate aerosol as a function of temperature, J. Geophys. Res., 104, D17, 21 317-21 326, 1999.

Pant, A., Fok, A., Parsons, M. T., Mak, J., and Bertram, A. K.: Deliquescence and crystallization of ammonium sulfate-glutaric acid and sodium chloride-glutaric acid particles, Geophys. Res. Lett., 31, 12, 2004.

Parsons, M. T., Knopf, D. A., and Bertram, A. K.: Deliquescence and crystallization of ammonium sulfate particles internally mixed with water-soluble organic compounds, Journal of Physical Chemistry A, 108, 52, 11 600-11 608, 2004.

Peng, C., Chan, M. N., and Chan, C. K.: The hygroscopic properties of dicarboxylic and multifunctional acids: Measurements and UNIFAC predictions, Environ. Sci. and Tech., 35, 22, 44954501, 2001.

Persiantseva, N. M., Popovicheva, O. B., and Shonija, N. K.: Wetting and hydration of insoluble soot particles in the upper troposphere, Journal of Environmental Monitoring, 6, 12, 939-945, 2004.

Peterson, R. and Tyler, B.: Surface composition of atmospheric aerosol: individual particle characterization by TOF-SIMS, Applied Surface Science, 203-204, 751-756, 2003.

Pio, C., Alves, C., and Duarte, A.: Organic components of aerosols in a forested are of central Greece, Atmos. Environ., 35, 389401, 2001.

Prenni, A. J., De Mott, P. J., and Kreidenweis, S. M.: Water uptake of internally mixed particles containing ammonium sulfate and dicarboxylic acids, Atmos. Environ., 37, 30, 4243-4251, 2003.

Raymond, T. and Pandis, S.: Formation of cloud droplets by multicomponent organic particles, J. Geophys. Res., 108, 4469, doi:10.1029/2003JD003503, 2003.

Rogge, W., Hildemann, L., Mazurek, M., Cass, G., and Simoneit, B.: Sources of fine organic aerosol: 9. Pine,oak, and synthetic $\log$ combustion in residential fireplaces, Environ. Sci. and Tech., 32, 13-22, 1998.

Rogge, W., Mazurek, M., Hildemann, L., Cass, G., and Simoneit, B.: Quantification of urban organic aerosols at a molecular level: Identification, abundance and seasonal variation, Atmos. Environ., 27A, 8, 1309-1330, 1993.

Rudich, Y., Benjamin, I., Naaman, R., Thomas, E., Trakhtenberg, S., and Ussyshkin, R.: Wetting of hydrophobic organic surfaces and its implications to organic aerosols in the atmosphere, J. Phys. Chem. A, 104, 22, 5238-5245, 2000.

Russell, L. M., Maria, S. F., and Myneni, S. C. B.: Mapping organic coatings on atmospheric particles, Geophys. Res. Lett., 29, 16, 2002.

Saxena, P. and Hildemann, L. M.: Water-soluble organics in atmospheric particles: A critical review of the literature and application of thermodynamics to identify candidate compounds, Journal of Atmos. Chem., 24, 57-109, 1996.

Seidl, W.: Model for a surface film of fatty acids on rain water and aerosol particles, Atmos. Environ., 34, 28, 4917-4932, 2000.

Shulman, M. L., Charlson, R. J., and Davis, E. J.: The effects of atmospheric organics on aqueous droplet evaporation, J. Aeros. Sci, 28, 5, 737-752, 1997.

Tabazadeh, A.: Organic aggregate formation in aerosols and its impact on the physico-chemical properties of atmospheric particles, Atmos. Environ., in press, 2005.

Tang, I. N. and Munkelwitz, H. R.: Composition and temperature dependence of the deliquescence properties of hygroscopic aerosols, Atmospheric Environment, 27A, 4, 467-473, 1993.

Tervahattu, H., Hartonen, K., Kerminem, V.-M., Kupiainen, K., Aarnio, P., Koskentalo, T., Tuck, A. F., and Vaida, V.: New evidence of an organic layer on marine aerosols, J. Geophys. Res., 107, D7, doi:19.1029/2000JD000282, 2002.

Tervahattu, H., Juhanoja, J., and Kupiainen, K.: Identification of an organic coating on marine aerosol particles by TOF-SIMS, J. Geophys. Res., 107, D16, doi:10.1029/2001JD001403, 2002.

Tervahattu, H., Juhanoja, J., Vaida, V., Tuck, A. F., Niemi, J., Kupiainen, K., Vehkamaki, K. M., and Vehkamaki, H.: Fatty acids on continental sulfate aerosol particles, J. Geophys. Res., 110, D06207, doi:10.1029/2004JD005400, 2005.

Thomas, E., Rudich, Y., Trakhtenberg, S., and Ussyshkin, R.: Water adsorption by hydrophobic organic surfaces:Experimental evidence and implications to the atmospheric properties of organic aerosols, J. Geophys. Res., 104, D13, 16 053-16059, 1999.

Tobias, D. J. and Klein, M. L.: Molecular dynamics simulations of a calcium carbonate calcium sulfonate reverse micelle, J. Phys. Chem., 100, 16, 6637-6648, 1996.

Wagner, J., Andrews, E., and Larson, S. M.: Sorption of vapor phase octanoic acid onto deliquescent salt particles, J. Geophys. Res., 101, 19533-19540, 1996.

Weingartner, E., Burtscher, H., and Baltensperger, U.: Hygroscopic properties of carbon and diesel soot particles, Atmos. Environ., 31, 15, 2311-2327, 1997. 
Wexler, A. and Seinfeld, J. H.: Second generation inorganic aerosol model, Atmos. Environ., 25A, 12, 2731-2748, 1991.

Wise, M. E., Surratt, J. D., Curtis, D. B., Shilling, J. E., and Tolbert, M. A.: Hygroscopic growth of ammonium sulfate/dicarboxylic acids, J. Geophys. Res.-A., 108, D20, 4638, doi:10.1029/2003JD003775, 2003.

Xiong, J. Q., Zhong, M., Fang, C., Chen, L. C., and Lippmann, M.: Influence of organic films on the hygroscopicity of ultrafine sulfuric acid aerosol, Environ. Sci. and Tech., 32, 3536-3541, 1998.
Xu, Q., DeWitte, M., and Sloan, J. J.: The effect of formic acid on the deliquescence of model sea-salt aerosol particle, Atmos. Environ., 37, 911-919, 2003.

Yaws, C.: Chemical Properties Handbook, New York, McGrawHill, 1999. 